American Journal of Applied Sciences 7 (12): 1593-1598, 2010

ISSN 1546-9239

(C) 2010 Science Publications

\title{
Revenue Determinants in Tourism Market
}

\author{
${ }^{1}$ Mohammad Mohebi and ${ }^{2}$ Khalid Abdul Rahim \\ ${ }^{1}$ Department of Business Management, Faculty of Management, \\ Hormozgan University, Bandarabbas, Iran \\ ${ }^{2}$ Institute of Agricultural and Food Policy Studies, University Putra Malaysia
}

\begin{abstract}
Problem statement: Malaysian tourism industry has been growing considerably in recent years. The number of tourist arrivals has grown by 25\% during 2006-2008. In comparison with Thailand and Singapore, Malaysia has more tourist arrivals but it has earned less income. The purpose of the study was to determine the major factors affecting inbound tourism expenditure in Malaysia. Approach: A panel data set for 14 origin countries, from 1998-2009 has been used to estimate tourism expenditure using gravity model. Results: The results of the expenditure model suggest that the Malaysian price index and distance have negative impact while per capita income of origin countries and Malaysian per capita income have positive impact on tourism expenditure. Conclusion: The own price elasticity indicates in short run that the tourism expenditure was inelastic to price. But in the long run tourism expenditure in Malaysia was elastic and potential tourists are more sensitive to the price changes. The lagged dependent variable's high coefficient (0.78) was represents that, our expectation has been right about consumer constancy to the destination. Based on the results, Singapore was a complementary destination meanwhile Thailand and Australia are substitute destination for Malaysia and finally SARS crisis negatively affected the tourism revenue.
\end{abstract}

Key words: Tourism expenditure, panel data, gravity model, origin countries, econometric, capita income, dependent variable, exchange rate, tourism demand, tourism revenue, lagged dependent

\section{INTRODUCTION}

Malaysian tourism industry has been growing considerably in recent years. Based on the statistics, the number of tourist's arrivals has grown by $25 \%$ during 2006-2008. During the same period, this rate has been $4 \%$ for Singapore and Thailand. But By comparison, although Malaysia has more number of tourism arrivals it has earned less income than Thailand and Singapore. In 2005, the tourism activities in Malaysia contributed about $7 \%$ of the national product and employs more than $10 \%$ of the total labor force. Furthermore, because it is the second largest foreign exchange earner, after industrial production the gains from tourism are the main source of income for financing the current account deficit. Malaysia received 22.05 million visitors and over 14.5 billion USD in returns from this industry in the year 2008 (www.tourism.gov.my).

On the world scale Malaysia, is ranked 31st, with good ground transport infrastructure and excellent price competitiveness. It is also ranked 2 nd in tax regime and in the government priority for travel and tourism. In terms of security and safety it is ranked 24th (World Tourism Organization, 2007).
Total tourist arrivals to Malaysia are more than 22 million in 2008 with an annually growth about of 5.1\% according to the Malaysian tourism ministry. Based on the statistics Singapore is a major source of tourist arrivals for Malaysia. Considering the growing importance of tourism it seems that studies on the international demand of tourism in Malaysia are scarce and inadequate. Basically tourism revenue can be divided into two parts, namely: private and public revenue, Tourism expenditure is a source of private revenue, meanwhile public returns of tourism comes from tax on tourism goods and services. Expenditure of tourism is one of the important sources of revenue for the private sector. There are many factors that affect tourism expenditure (such as destination price, substitute price, number of tourist arrivals, exchange rate and per capita income in generation countries). For this reason in this study we use a model of tourism expenditure to determine these factors in Malaysian tourism market. A theoretical framework based on the gravity model is used to specify our tourism expenditure model. Based on trade gravity models, distance and prices in other countries also have impact

Corresponding Author: Mohammad Mohebi, Department of Business Management, Faculty of Management, 
on trade between the two countries. To estimate the expenditure model a panel data set for 14 origin countries, from 1998-2009 is used in this study. Tourism expenditure from the 14 major origin countries (i $=1, \ldots, 14$ ) comprises more than $85 \%$ of tourism arrivals to Malaysia. These countries are Singapore, Thailand, Australia, Taiwan, Saudi Arabia, Brunei Darussalam, China, Hong Kong, Indonesia, Japan, Philippine, United Kingdom, Germany and United States. The annual data set for the 11-year period between 1998 and 2009 give us 154 observations.

\section{Tourism expenditure model:}

Gravity model: Gravity model among many trade models is quite successful in economics and applied social sciences. This model is derived from Newton's law that the force which increases with mass and decreases with distance in physics is identified as gravitation. Newton's Law of Universal Gravitation:

$F_{i j}=\frac{G M_{i} M_{j}}{D_{i j}{ }^{2}}$

Where:
$\mathrm{F}=$ Attractive force
$\mathrm{M}=$ Mass
$\mathrm{D}=$ Distance
$\mathrm{G}=$ Gravitational constant

For econometric analyses we can change it into a linear form using logarithms. The following specification is usually used in international trade that is similar in all studies:

$$
\mathrm{VT}_{\mathrm{kj}}=\alpha\left(\mathrm{Y}_{\mathrm{k}}\right)^{\beta 1}\left(\mathrm{Y}_{\mathrm{j}}\right)^{\beta 2}\left(\mathrm{~N}_{\mathrm{k}}\right)^{\beta 3}\left(\mathrm{~N}_{\mathrm{j}}\right)^{\beta 4}\left(\mathrm{D}_{\mathrm{kj}}\right)^{\beta 5}\left(\mathrm{Z}_{\mathrm{kj}}\right)^{\beta 6}\left(\mathrm{u}_{\mathrm{kj}}\right)
$$

Where:

$\mathrm{VT}_{\mathrm{kj}} \quad=$ The value of the flow from nation $\mathrm{k}$ to nation $\mathrm{j}$,

$\mathrm{Y}_{\mathrm{k}}$ and $\left(\mathrm{Y}_{\mathrm{j}}\right)=$ The supposed value of Gross Domestic Product (GDP) in $\mathrm{k}$ and $\mathrm{j}$

$\mathrm{N}_{\mathrm{k}}$ and $\mathrm{N}_{\mathrm{j}}=$ The size of population in both countries

$\mathrm{D}_{\mathrm{kj}} \quad=$ The distance between $\mathrm{k}$ and $\mathrm{j}$, while

$\left(\mathrm{Z}_{\mathrm{kj}}\right) \quad=\mathrm{A}$ vector of other variables also assisting or opposing the flow between $\mathrm{k}$

$\mathrm{j}$ and $\mathrm{u}_{\mathrm{kj}} \quad=$ Distributed error term

In the field of tourism Gravity models, theoretical base of the model as suggested by Bergstrand (1985) can be constructive to explain foreign tourism demand in a particular country. Travelling for tourism purposes has a fundamental idea behind it which is that places are diverse and are unrivaled; therefore destinations for tourists are not absolutely substitutable (Durbarry, 2001).

The vacationers are forced to pay tax charges, transport costs and as well as currency exchanges. The general gravity model that is specified for tourism is as follows:

$\mathrm{Y}_{\mathrm{kjt}}=\alpha_{\mathrm{k}}+\gamma_{\mathrm{j}}+\lambda_{\mathrm{t}}+\beta_{1} \mathrm{X} 1_{\mathrm{kjt}}+\beta_{2} \mathrm{X} 2_{\mathrm{kt}}$ $+\beta_{3} \mathrm{X} 3_{\mathrm{kt}}+\ldots \ldots \ldots+\mathrm{u}_{\mathrm{kjt}}$

where, $Y_{\mathrm{kjt}}$ is the volume of trade from country $\mathrm{k}$ to country $\mathrm{j}$ at time $\mathrm{t}$, as dependent variable $\mathrm{X} 1 \mathrm{kjt}$ are explanatory variables with dissimilarity in all three dimension $\mathrm{k}, \mathrm{j}$ and $\mathrm{t}$, for example exchange rate, $\mathrm{X} 2_{\mathrm{kt}}$ are explanatory variables with discrepancy in measurement $\mathrm{k}$ and $\mathrm{t}$. For instance gross domestic product, $\mathrm{X} 3_{\mathrm{jt}}$ is an explanatory variable with disparity in dimensions $\mathrm{j}$ and $\mathrm{t}, \alpha_{\mathrm{k}}$ is the origin country effect, $\gamma_{\mathrm{k}}$ is the destination country effect, $\lambda_{t}$ is the time effect and $\mathrm{u}_{\mathrm{kjt}}$ is a white noise disturbance term. The precise effects $(\alpha, \gamma$ and $\lambda)$ can be treated as random variables (Error Component Approach) or fixed parameters (fixed effect approach) when estimating such a model.

The amount paid for the acquisition of consumptions goods and services, as well as valuables, for personal or public use, which is for the trip is referred to as tourism expenditure. This tourism expenditure includes expenditure by visitors themselves in addition to expenses that are paid for or reimbursed by others. It is comprehensive of VAT and other taxes. In stipulations of the major factors influencing the expenditure for tourism, the most commonly used variables are income and prices (Lim, 1999). People are more inclined to travel as their income increases. Tourists are susceptible to transportation costs and destination cost of living includes accommodation, meals. This variable is captured by the distance factor in the model. Potential visitor may change destination if the costs of living are relatively high and also, they might try to find a cheaper destination or prefer domestic trip. To measure the cost of living in one destination appropriate variables that could be used are relative prices of lodging services and restaurants. But in this study in the absence of the above mentioned data we use inflation rate in the destination that is adjusted by exchange rate as the cost of living in destination based on purchasing power parity concept.

The tourism expenditure model for specification in this study follows the empirical model of Durbarry (2001) a gravity based model which looked at the influence of world income, relative prices and distance 
on tourism expenditure. Our model uses Malaysian tourism receipts as the dependent variable. In this study, Feasible Generalize Least Square (FGLS) estimator with Panel data is used to estimate the expenditure for tourism in Malaysia. Its specification is given as:

$$
\begin{aligned}
& \ln \mathrm{EXP}_{\mathrm{mjt}}=\varphi_{0}+\alpha_{\mathrm{i}}+\lambda_{\mathrm{t}}+\beta_{1} \ln \mathrm{Y}_{\mathrm{Mt}}+ \\
& \beta_{2} \ln \mathrm{Y}_{\mathrm{jt}}+\beta_{3} \ln \mathrm{DIST}_{\mathrm{Mj}}+\beta_{4} \ln \mathrm{P}_{\mathrm{Mjt}} \\
& +\beta_{5} \ln \mathrm{P}_{\mathrm{kjt}}+\ln \mathrm{EXP}_{\mathrm{Mjt}}(-1)+\mathrm{U}_{\mathrm{Mjt}}
\end{aligned}
$$

Where:

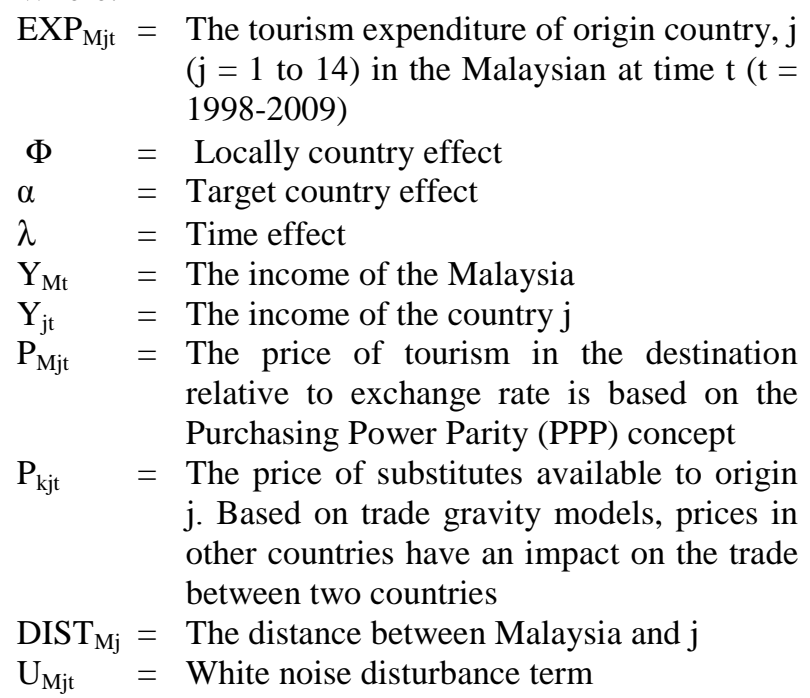

For econometric reason, in panel equation we can logically treat the specific effects as random variables and use the FGLS estimation method Especially, in the case of the presence of some 'size' variables such as distance and GDP because it may be rise to heteroscedasticity (Durbarry, 2001).

Data: Expenditure of tourism is considered as being a more suitable variable for evaluating the tourism demand rather than the tourist arrival or any other variables because the increasing flow of tourist do not necessarily show an increasing revenue in destination (Durbarry, 2001).

Our study is the first attempt to modeling tourism expenditure in Malaysia which considers tourism expenditure as the dependent variable. Unfortunately the yearly data of expenditure of tourism by country are not available. Therefore we use available information about expenditure share by country to calculate the tourism expenditure data by country. In our model explanatory variables include the per capita GDP of generation countries (YG) as income variable, substitute price referring to average of destination Price
(PG), In computing the price variable PG, we used a method that was applied before by Durbarry (2001) in the UK tourism expenditure model which obtained from the following term:

$$
\ln \mathrm{p}_{\mathrm{mjt}}=\ln \left[\sum \mathrm{x}_{\mathrm{kt}}\left\{\frac{\mathrm{cpi} \mathrm{kt}_{\mathrm{kt}} \times \mathrm{xE}_{\mathrm{Mt}}}{\mathrm{cpi} \mathrm{i}_{\mathrm{m}} \cdot \mathrm{xE}_{\mathrm{K}, \text { base }}}\right\}\right]
$$

Where:

$\mathrm{X}=\mathrm{A}$ weight and is the proportion of tourists visiting destination from country $\mathrm{j}$ at time $\mathrm{t}$, where $\mathrm{k}=1 \ldots \ldots \mathrm{n}$ excluding the Malaysian

$\mathrm{E}_{\mathrm{m}}=$ The exchange rate between $\mathrm{k}$ and Malaysia

$E_{\mathrm{k}, \text { base }}=$ The exchange rate in the base year

We used the GDP of origin country in per capita terms as the income measure to capture the welfare effect in the expenditure model. Based on the tourism economic theory the arrival of tourist is an encouraging factor for another person that will be travelling to a certain destination.

The justification of including a lagged dependent variable in tourism models were discussed by GarinMunoz (2007). Provided two possible justifications, firstly, uncertainty about a destination that will meet for the first time is more than of any place that a person already visited. In addition tourist is generally risk averse and may feel more contented in choosing the same previous destination country. Secondly, as people talk about their holiday experience knowledge about the destination extends, thus decreasing the uncertainty for tourist to that destination. According to Song and Witt (2000) in any year the number of tourists who select a certain destination depends on the number of tourist arrivals in the previous years. There are many studies that used the lagged dependent variable to explain the tourism demand. For example Habibi et al. (2009); Martin and Witt (1987) Fujii and Mak (1981) GarinMunoz (2007) Witt and Martin (1987). Also, we used the Malaysian GDP (YM) as an explanatory variable. In this model, YM corresponds to the attraction capacity of the destination and is associated with the supply capacity. In order to study more precisely we included the price of Singapore (SP), Thailand (TP), Indonesia (IP), China (CP) and Australia (AP) as a variable separately in the model. Tourism price is a measure for costs of living in a destination by the tourists. In our model the inflation rate is used as a proxy for the cost of living in the destination relative to the exchange rate. The value of exchange rate is computed by the purchasing power parity: 
Am. J. Applied Sci., 7 (12): 1593-1598, 2010

$$
\mathrm{Pi}=\frac{\mathrm{INF}}{\mathrm{EX}}
$$

Where:

$$
\begin{aligned}
\mathrm{Pi}= & \text { Cost of living in destination } \mathrm{i} \\
\mathrm{INF}= & \text { Inflation rate of destination and EXis exchange } \\
& \text { rate of destination }
\end{aligned}
$$

This term comes from the purchasing power parity concept. Other variables included in the model are the distance between Malaysia and generating countries (DIST) and dummy variables. Annual data for 14 most important generating countries during the period 19982009 were used in this model. All data from Malaysia and the fourteen origin countries were obtained from the Tourism Statistics by the Ministry of Tourism Malaysia (2010), the International Financial Statistics (2007) and International Monetary Fund-2009 (World Economic Outlook).

\section{MATERIALS AND METHODS}

Our attempt to model inbound tourism expenditure for Malaysia is based on the gravity model with the panel data approach. In the first step we applied the LM test to choose between the pool and panel method. The null hypothesis is that cross-sectional variances components are zero. The results of the LM test show that our model is panel (random).In the second step, we applied the Hausman test to choose between the fixed and random effect methods. The results of the Hausman test show that our model is random (Hausman and Taylor, 1981). The $\mathrm{H}_{0}$ is that the individual effects have no correlation with the other variables in the model. This is because in our model we have included the distance variable that is fixed on time. According to Wooldridge (2007) these types of models are random models. Finally, we used the error component analysis to choose between one or two-way causality and the results show that our model is flexible to choose any. The results of the Durbin- test statistics indicate that there is not any evidence of serial correlation in the expenditure equations, based on the Durbin's h-statistic

\section{RESULTS AND DISCUSSION}

In our panel model, shown in Table 1 all of the findings are consistent with the theory. The coefficient of determination the $\mathrm{R}^{2}$, indicates that $91 \%$ of the total variation in tourism expenditure can be explained by including variables in the expenditure model .It should be noted that we have used the lagged dependent variable as an explanatory variable. Without this variable the $R^{2}$ statistic was 0.80 .
Table 1: Result of the panel estimation expenditure equation

\begin{tabular}{lrl}
\hline Variables & & Coefficient \\
\hline C & -2.88 & $(-1.44)^{*}$ \\
LEXPG (-1) & 0.78 & $(16.46)^{* * *}$ \\
LYM & 1.18 & $(2.38)^{* *}$ \\
LYG & 0.04 & $(4.65)^{* * *}$ \\
LDIST & -0.08 & $(-2.67)^{* * *}$ \\
SP & -0.14 & $(-2.03)^{* *}$ \\
LPG & 0.02 & $(2.18)^{* *}$ \\
AP & 0.20 & $(12.71)^{* * *}$ \\
MP & -0.69 & $(-2.22)^{* *}$ \\
TP & 0.54 & $(2.17)^{* *}$ \\
D03 & 0.70 & $(4.49)^{* * *}$ \\
$R^{2}=0.91$ & & DW $=2.14$ \\
\hline Note: Significance levels denoted as follows ***: $(1 \%), * * ;(5 \%)$ and \\
*: (10\%), t- ratios in parentheses
\end{tabular}

Income: The results indicate that the coefficient for the income of generation countries is 0.2 in the short run and 0.9 in the long run. An increase in the income, with other things being equal, will increase $0.9 \%$ the expenditure in the long run. The global economic crises have less effect on the Malaysian tourism revenue. Since the elasticity of income in expenditure model is less than a unit and it means that that tourism in Malaysia is considered by fourteen major countries as not a luxury. The long run elasticity of income is equal to 0.9 thus the Malaysian inbound tourism expenditure in the long run remained inelastic in terms of income.

Own price elasticity: Own price elasticity of expenditure is a measure of the percentage change in the expenditure caused by a percentage change in price. In our model the own price elasticity is coefficient of cost of living in Malaysia (MP) and it is equal to -0.69 , that indicates in short run the tourism expenditure is inelastic to price. But in the long run the result suggests that the tourism expenditure in Malaysia is elastic $\mathrm{e}=(-3.45)$ and potential tourists are more sensitive to the price changes. This result was supported by Habibi and Rahim (2009b) and Norlida et al. (2007). The own price elasticity for demand of tourism as estimated by Habibi were -0.6 and -6.1 in the short run and long run respectively.

Cross price elasticity: the price in competing destination has clear effect on the Malaysian tourism revenue. The elasticity of average substitution price is 0.04 in the short run and 0.2 in the long run. As mentioned, in order to study more precisely we included the price variable in Singapore (SP), Thailand (TP), Indonesia (IP), China (CP) and Australia (AP) separately in the model because the PG was an average price and it could not be a good criteria for our purpose. Since, in the estimate model, the Indonesian Price (IP) and Chinese Price (CP) were not significant we omitted 
these variables from the model. The result highlights that Singapore is not a competing destination for Malaysia because the elasticity of Singaporeans price has negative sign $(-0.14)$ in the short run and 0.6 in the long run. Thus, it seems that this country is a complement for the Malaysian tourism industry although it is not fully complementary. Meanwhile Australia and Thailand are substitute destinations. The coefficient of Indonesian price is negative but insignificant and China's price has a positive sign and also insignificant therefore these variables were omitted from the model.

These results explain that one unit increase in Thailand's cost of living will bring a $0.54 \%$ increase in the Malaysian revenue from tourism in the short run and $2.4 \%$ change in the long run. We can conclude that any increase in the living cost in Malaysia can divert the potential Malaysian tourist to Thailand.

Travel cost: We used distance into the expenditure model as a proxy for travel cost. The coefficient of distance is negative and significant $(-0.05)$, it is consistent with theoretical expectations. Although this coefficient is negative and indicated the travel cost is a factor for potential tourism but it is not high enough that in the absorption of tourism from near and far Malaysia has been successful despite this high travel cost, Malaysian tourism attraction plans have been able to attract tourism from around the world. But the negative sign of travel cost indicates that planning to reduce travel costs is necessary for tourism management.

Lagged dependent variable: The lagged dependent variable's coefficient is significant (0.78). This coefficient was previously estimated by Habibi (0.9) for Malaysian demand tourism model (Habibi et al., 2009). This result represents that, our expectation has been right about consumer constancy to the destination. Based on the tourism economic theory the arrival of tourist is an encouraging factor for the other person who is travelling to a certain destination. Therefore improvement in their service quality and upgrading their brand image is important for the Malaysian tourism supply sector operators. Also, in this model the dummy variable D03 has been included to reflect the impact of the SARS crisis in 2003. The results show negative effects of this crisis on the Malaysian tourism revenue.

\section{CONCLUSION}

To estimate the expenditure model a panel data set for 14 origin countries, from 1998-2009 are used in this study. These countries comprise more than $85 \%$ of tourism arrivals to Malaysia These countries include Singapore, Thailand, Australia, Taiwan, Saudi Arabia, Brunei Darussalam, China, Hong Kong, Indonesia, Japan, Philippine, United Kingdom, Germany and United States. The annual data set for the 11-year period between 1998 and 2009 give us 154 observations. The results suggest that expenditure of tourism in Malaysia is sensitive to price in the long run. The results also reveal that exchange rate is not a significant determinant of tourism expenditure due to it being constant for 2002-2006. On the other hand, the Malaysian price index and distance have negative effects on the tourism expenditure. Our results also show that the coefficient of tourism price of Singapore is negative and positive for Australia and Thailand, therefore Singapore is a complementary destination meanwhile Thailand and Australia are substitute destination for Malaysia. Other variables such as per capita income of origin countries and Malaysian per capita income have positive impact on tourism expenditure. The results also indicate that SARS crisis negatively affected the tourism revenue.

\section{REFERENCES}

Bergstrand, J.H., 1985. The gravity equation in international trade: Some microeconomic foundations and empirical evidence. Rev. Econ. Stat., 67: 474-481. http://www.jstor.org/pss/1925976

Durbarry, R., 2001. Tourism expenditures in the UK: Analysis of competitiveness using a gravity-base model. http://www.intute.ac.uk/cgibin/fullrecord.pl?handle $=20240444$

Fujii, E.T. and J. Mak, 1981. Forecasting tourism demand: Some methodological issues. Ann. Regional Sci., 15: 72-82. DOI: 10.1007/BF01287440

Garin-Munoz, T. and F.L. Matrin, 2007. Tourism in the Balearic Islands: A dynamic model for international demand using panel data. Tourism Manage., 28: 1224-1235. DOI: 10.1016/j.tourman.2006.09.024

Habibi, F. and K.A. Rahim, 2009b. A bound test approach to cointegration of tourism demand. Am. J. Applied Sci., 6: 1924-1931. DOI: 10.3844/.2009.1924.1931

Habibi, F., K.A. Rahim, S. Ramchandran and L. Chin, 2009. Dynamic model for international tourism demand for Malaysia used panel data approach. Int. Res. J. Fin. Econ., 336: 207-217. ISSN: 1450-2887 
Hausman, J.A. and W.E. Taylor, 1981. Panel data and unobservable individual effects. Econometrica, 49: 1377-1398. DOI: 10.1016/0304-076(81)90085-3

Lim, C.A., 1999. A meta-analytic review of international tourism demand. J. Travel Res., 37: 273-284. DOI: 10.1177/004728759903700309

Martin, C.A. and S.F. Witt, 1987. Tourism demand forecasting models: Choice of appropriate variable to represent tourists cost of living. Tourism Manage., 8: 233-246. DOI: 10.1016/02615177(87)90055-0

Norlida, H., M. Salleh and O. Redzuan and R. Sridar, 2007. Malaysia's tourism demand from selected countries: The ARDL approach to co-integration. Int. J. Econ. Manage., 1: 345-363. ISSN: 1823$836 \mathrm{X}$
Song, H. and S.F. Witt, 2000. Tourism Demand Modeling and Forecasting: Modern Econometric Approaches. 1st Edn., Oxford, Elsevier Science LtdTan, U.K., pp: 186. ISBN-10: 0080436730

Witt, S.F. and C.A. Martin, 1987. Appraising an econometric forecasting model. J. Travel Res., 28: 30-34. DOI: $10.1177 / 004728759002800305$

Wooldridge, J., 2007. Introductory Econometric a Modern. 4th Edn., MIT Press, USA., pp: 491. ISBN-13: 978-0-324-58162-1

World Tourism Organization, 2007. Tourism highlights, (various issues). Tourism http://www.tsoshop.co.uk/bookstore.asp?fo=1160663 